\title{
Ese íntimo desconocido
}

\author{
Black mirror | Jodie Foster | 2011; The Handmaid's Tale | Bruce Miller | 2017; \\ Little fires everywhere | Lynn Shelton | 2020 \\ Celeste Viñal*
}

AMP, EOL | Hospital Interzonal General de Agudos “Gral. San Martín”, La Plata, Argentina

Recibido: 5 de agosto 2020; aceptado: 13 de octubre 2020

\begin{abstract}
Resumen
Una pandemia trae múltiples resonancias en los sujetos, la sociedad e incluso, en la práctica del psicoanálisis. El escenario actual permite visibilizar, en esta coyuntura, a un Otro que tambalea en sus semblantes de saber, de gobernar, de curar. Estamos aún sin perspectiva, pero podemos esbozar algunas ideas sueltas, si uno puede desamarrarse un poco de sus amores con la Verdad, la exactitud y el magister dixit. El presente trabajo recorre diversos efectos de la pandemia teniendo en cuenta un neologismo de Lacan, que Miller retomó en su Curso y que permite ubicar distintas intimidades externas o externalidades íntimas. La extimidad, se presenta entonces en este ensayo como un aporte conceptual desde el cual resulta posible trazar diversas reflexiones sobre nuestra actualidad. A partir de allí y teniendo en cuenta contribuciones del arte, resultará posible reflexionar acerca de los procesos de segregación, una de las problemáticas que atraviesa con notable presencia nuestra sociedad actual.
\end{abstract}

Palabras clave: Pandemia | psicoanálisis | extimidad | actualidad

That intimate stranger

Abstract

A pandemic brings multiple resonances in the subjects, society and even in the practice of psychoanalysis. The current scenario makes it possible to see, at this juncture, an Other that staggers in its countenances of knowing, of governing, of healing. We are still out of perspective, but we can sketch out some ideas, if we can untie a little from our love with truth, exactitude and magister dixit.

The present work covers various effects of the pandemic taking into account a neologism by Lacan, which Miller took up in his Course and which allows locating different external intimacies or intimate externalities. Extimacy is then presented in this essay as a conceptual contribution from which it is possible to trace various reflections on our present time.

From there and taking into account the contributions of art, it will be possible to reflect on the processes of segregation, one of the problems that our current society is going through with a notable presence.

Keywords: Pandemic I psychoanalysis I extimacy I present time

"Es duro ser negro. ¿Has sido negro alguna vez? Yo fui negro una vez... cuando era pobre”.

Larry Holmes, Ex campeón WBC de pesos pesados.

La productividad random ${ }^{1}$ es una forma posible de habitar esta cuarentena. Por ahora es la única a la que tuve acceso. La atención fluctúa, se disipan las ideas en horas y cobran formas tan extrañas como su propio anverso. Nada es demasiado prolijo. Se suceden los días atrapados en un tiempo que muta de interminable a instantáneo. Un raro loop moebiano. Nada está del todo en su lugar, nos enfrentamos a miedos propios y ajenos. A desafíos. En el mejor de los casos somos espectadores del horror de otros, cuando no del propio. Nos invade esa atmósfera pesada y global que generó la pandemia.

Se improvisan recursos personales, grupales, profesionales. Como psicoanalistas nos enfrentamos a una práctica que nos resta el cuerpo como herramienta. De todos modos intentamos poner en forma el deseo del analista bajo maneras versátiles de llevarlo adelante. Insistimos en sostener nuestros espacios de formación, de control. Se inventan ofertas clínicas a la comunidad, se arman grupos de atención sanitaria a quienes están en directa exposición al virus.

Pensamos una y otra vez cómo argumentar con lo que ya tenemos las invenciones que tratan de enfrentarse a lo nuevo.

mcelestev@gmail.com 
Es manifiesto el cansancio que produce el intento de reproducir las condiciones de un análisis por estos medios. La atención flotante en los primeros días no lograba su necesaria levedad y el logos empañaba las intervenciones. Los cortes de sesión necesitaban tomar en cuenta la distancia que impone la mediación de los dispositivos. Hemos ido variando, ensayando, encontrando modos de hacerlo posible. Pero conlleva reformulaciones imprevistas, aceptar que estamos frente a lo desconocido de una práctica que requiere toda nuestra atención.

Quizás haya que considerar estos esfuerzos extra para disculparse por algunas omisiones o ciertas demoras. No todo puede estar igual frente a circunstancias tan inusuales.

Cuando recibí la invitación a participar en este espacio me entusiasmé mucho pero al momento de sentarme a escribir, ese inicial ímpetu se agobió en un océano de responsabilidad del que no parecía poder emerger. En primera instancia hice lo que siempre me sale hacer: leer.

Vagué por lecturas variadísimas, todas interesantes, pero ninguna daba la pista del sesgo que necesitaba encontrar, el hilo de Ariadna con el cual pudiera orientarme. Me ramificaba, la metonimia me condenaba a una errancia sin fin.

Una de las características más frecuentes de la neurosis es la indeterminación. Ok, touché ${ }^{2}$, se me había neurotizado la propuesta. Y como de original no solemos tener casi nada, lo había hecho como ya me tiene acostumbrada, por el lado del viejo y jamás estimado superyó.

Sabemos que es imposible constituirse como yo sin esa intromisión que llega del campo del Otro del lenguaje que torna lo exterior en interior con esa orden cruel e insensata que hace de contrapunto al Nombre del Padre, conocido operador que se coordina mucho mejor al deseo. Pero ese mandato resuena justamente en el vacío del Otro, en esa ausencia de garantía. ¡Y...qué actual resulta! Entonces obtengo al menos una duplicación de esa inconsistencia.

Pasan los meses, pesados como yunques, tan livianos que se escurren o en los miles de matices intermedios. Pasa el tiempo e intentamos comprender a qué mundo vamos a emerger. El mundo nunca fue homogéneo pero ahora parece serlo menos.

Las experiencias con el virus son extremadamente disímiles. Ominosamente azarosas. Las personas reaccionan muy distinto a nivel orgánico y también conductualmente. Aterrados conviven con temerarios, pocos se mantienen en su eje, si es que esto existiese sin pandemia. Pocos que no experimenten la profunda vulnerabilidad a la que esta crisis global nos ha enfrentado.
Estalla ante nosotros la pretendida homogeneidad de un imaginario globalizado. Fragmentos que buscan un público, una audiencia que busca un teatro que se experimenta por WhatsApp (no es lo mismo claro, otra vez el cuerpo que falta), nos alimentamos de películas y series, jugamos a mostrar lo que cocinamos como en un reality extendido por las redes que nos permite ver cómo sobreviven otros. $\mathrm{Y}$ esas opciones suelen parecer mejores, menos agobiantes, más distendidas. Esas comparaciones que escuchamos en la clínica diaria: "ella sabe maquillarse para un vivo de Instagram", "él sí se fue a convivir con su novia", "ella tiene mantel nuevo", "pucha, a él se le murió el padre"... (fade to black)

Nadie sabe, nos aferramos a saberes parciales que nos resultan "más confiables" hasta que ese ejemplo oscilante también se cae y nos queda el silencio de la calle. Esa insistencia en que no haya vida afuera.

De nuevo: con familia, sin familia, en pareja, solos o como sea vuelve esa extraña compañía de uno mismo. En la ausencia de un Otro que dé cuenta de lo que pasa, por bondad o maldad pero que explique alguna trascendencia. Nada. O merecimiento (teorías sobre una supuesta venganza de la Tierra) pero como dice Lacan (1954), los astros no hablan. Nosotros los hacemos hablar y no nos estaríamos poniendo de acuerdo en decodificarlos.

Por todo eso la pandemia visibiliza a un Otro que tambalea en sus semblantes de saber, de gobernar, de curar. Los comités de especialistas intentan dar cuenta de ese real del desconocimiento en cuanto al virus se refiere y calculan todo lo posible ejes que parecen escaparse de la previsión. Los modelos de corte totalitario rechazan las consecuencias y enfrentan con supuesto gesto de "valentía" luctuosos destinos para miles de sus gobernados. Pero ya no se puede desmentir la evidencia, la muerte se ha instalado más allá de su captación de contingencia siendo una amenaza plural y abarcativa para todo organismo.

Entonces, escribir sobre pandemia durante la pandemia es un esfuerzo en sí mismo, más allá de cualquier tendencia al goce superyoico. Estamos aún sin perspectiva, pero podemos esbozar algunas ideas sueltas, si uno puede desamarrarse un poco de sus amores con la Verdad, la exactitud y el magister dixit.

El yo, ese parásito del superyó heredero de la extranjeridad que nos habita. Sólo podemos pensarnos con categorías que nos vinieron del afuera, con herramientas que ya estaban allí mucho antes de nuestro advenimiento al mundo. Sólo un análisis llevado hasta sus últimas consecuencias podrá extraer en su final el saldo, modesto, de 
nuestra singularidad, nuestra máxima diferencia, algo así como "lo propio".

Jacques-Alain Miller (2010) ha dedicado un curso entero al tema de esas formas de intimidades externas o externalidades íntimas. Utiliza un neologismo creado por Lacan, extimidad.

Así dio en llamar a las clases que se prolongan desde el 13 de Noviembre de 1985 hasta el 18 de Junio del $\$ 86$. Es el curso inmediatamente posterior a 1,2,3,4 y el anterior a Los signos del goce.

Luego fueron publicadas en su versión en castellano en el 2010 manteniendo una estricta vigencia que atraviesa 34 años. En esta coyuntura histórica y con los movimientos sociales que se están produciendo, donde los reclamos masivos en repudio al racismo, la violencia machista, el clasismo y los modos locales que toma la segregación son noticias cotidianas, el concepto de extimidad nos es -una vez más- operativo para pensar la actualidad.

Haciendo un poco de historia vemos cómo algunos términos pasan, mejor o peor utilizados al ámbito público desde el psicoanálisis. Siempre ha funcionado así, sobre todo en Argentina, donde éste discurso todavía tiene alguna representatividad, de la que somos absolutamente responsables en mantener vigente.

Extimidad de hecho es uno de ellos. Ha, inclusive, tomado en estos años un uso completamente diferente del que le provee Lacan al inventarlo como neologismo.

En estas lecturas peregrinas de cuarentena me he encontrado con que extimidad ha sido usado por algunos focos culturales como aquello que da cuenta de lo íntimo que se da a ver sin demasiado velo, de la exposición de la intimidad. Es un término que encontré utilizado tanto para ubicar el mecanismo de los reality shows al mostrar en directo la intimidad de una convivencia humana, por ejemplo, como la manera en la que el diario íntimo puede haber devenido blog o vlog (de hecho se lo nombra como diario éxtimo).

También lo encontramos llevado al terreno de la llamada Literatura del yo. Para ser breves en su definición tomemos una cita de Paola Cortés-Rocca que se encuentra en el prólogo de Un final feliz libro de Gabriela Liffschitz en el que se cuenta un final de análisis lacaniano que no llega al pase, Paola Cortés Rocca dice que son esos tipos de escritos en los que "el yo que habla es fácilmente confundido con el yo que firma" $(2009$, p.4) son objetos y prácticas que vacían las categorías de la literatura misma y ya no importa si lo son o no.

Son muchos los debates que existen acerca de eso, una literatura de la que se discuten los inicios. Ya en 1935
Máximo Gorki invitaba a los escritores a narrar un día de sus vidas, específicamente el 27 de Septiembre y hay disponibles más antecedentes aún en los que no me interesa profundizar.

La referencia nos es interesante ya que tomaron éxtimo para señalar, en este caso, aquello interno que se construye en el afuera, pero que no deja de evocar una exaltación mostrativa de lo íntimo. Los franceses lo llaman "ombliguismo”. También así lo llama Yasmina Khadra, un ex comandante del ejército argelino que para no abandonar su tarea militar escribió bajo un pseudónimo de mujer y es el autor árabe vivo más leído en la actualidad, él elige ser ella y desde esa voz poética denuncia que en la literatura europea hay mucho ombliguismo, etnocentrismo y narcisismo.

Vemos como si avanzamos en este terreno aparece un giro de lo íntimo a lo regional, a lo territorial, inclusive racial y sexual.

Justamente estos temas nos devuelven directamente al curso de Miller, que tantos años atrás rescataba el término de invención lacaniana para tensar más aún la cuerda de la lógica como motor del desarrollo de la teoría psicoanalítica.

En la clínica, según me lo han enseñado, la lógica genera efectos de adivinación. Miller (2010) se "anticipa" a situar con toda claridad en perspectiva a la extimidad con el racismo.

Pero aislando el destino para este concepto que Lacan le había reservado: la extimidad no es una mostración solipsista.

Extimidad es un concepto que nombra justamente lo que no puede decirse. Un concepto paradójico en tanto se trata de aquello que nos resulta más próximo, más interior, sin dejar de ser exterior.

Por eso ubica a la extimidad como la razón para que Lacan, hacia su última enseñanza, haya tenido que recurrir a la topología. El concepto de adentro-afuera, interno-externo se ve complicado por esa fisura en el seno de la identidad, de este adentro en el exterior. Recurre en principio a la figura del toro para mostrarlo.

Debemos señalar de inmediato que esta estructura (el toro) es la estructura de la extimidad: Esa estructura es diferente de la espacialización de la circunferencia o de la esfera en la que algunos se complacen en esquematizar los límites de lo vivo y de su medio. De querer dar una representación intuitiva suya, parece que más que a la superficialidad de una zona, es a la forma tridimensional de un toro a lo que habría que recurrir, en virtud de que su exterioridad periférica y su exterioridad central no constituyen sino una única región. De este modo describe la 
intuición que puede tenerse de la representación del toro, de la cámara de aire, debido a que hay confusión de identidad entre lo periférico y lo central. Es decir que ya entonces Lacan expone una representación del más interior que lo más íntimo mío, de San Agustín, ya entonces muestra el toro como una estructura de extimidad. Precisamente, esto distingue a la experiencia analítica de toda empresa fundada en un conócete a ti mismo, aunque pueda parecerse a eso. Para que el conócete a ti mismo pueda conducir a algo, debe sustentarse - en todo caso, para nosotros hoy - en la garantía del axioma de una identidad consigo mismo constitutiva de la intimidad subjetiva. Se trata de saber si lo que Freud llama y Lacan retorna como el núcleo de nuestro ser es idéntico a sí mismo. Ya puede decirse, a partir de lo que propusimos los años anteriores, que ciertamente el sujeto en el análisis se constituye como no idéntico a sí mismo. Esto es incluso lo primero que me sorprendió en la enseñanza de Lacan. No puede escribirse la ecuación que haría al sujeto idéntico a sí mismo. No puede escribirse $\mathrm{S}=\mathrm{S}$. Solo puede escribirse $\mathrm{S} /$. Si bien puede escribirse yo $=$ yo, no puede escribirse $S=S$. No nos quedaremos en este punto, ya que será necesario llegar a algo que, sin ser idéntico a sí mismo, tenga peso para el sujeto, sea central para él. (Miller, 2010, p.19)

Por lo tanto, no existe posibilidad alguna de exponer o disimular esa exterioridad interna ya que es el mismo Yo, ese del que hablábamos antes, el primero que la desconoce sistemáticamente.

Es un término para designar de una manera problemática lo Real en lo Simbólico. Sale de la bipartición externo-interno y nos confronta a que en la experiencia analítica lo íntimo es exterior. El sujeto es hablado, no es un punto de transparencia sino de opacidad.

Ya en La Instancia de la Letra, Lacan (1957) nos advierte que nos agita ese Otro con el cual estamos más ligados que con nosotros mismos.

La exterioridad del Otro se manifiesta en la vacilación de la identidad del sujeto, especialmente en la experiencia como analizante.

Entonces no se trata allí de elegir exponerse o reservarse, no es el Yo el que decide hasta dónde llegar en el relato, ni se trata tampoco de la ingenua pretensión de decirlo todo.

El análisis de orientación lacaniana es un procedimiento que desmantela permanentemente los artilugios de la voluntad de decir del Yo. Cuela en lo más íntimo alojado en la ruptura misma de la propia identidad, en una experiencia con el lenguaje que lleva a desconocer profundamente en las propias palabras proferidas. Muestra allí la singularidad que al mismo tiempo se fundó sin el Otro.

Si bien el análisis es íntimo (es quizás el lugar donde se espera encontrarse con lo más íntimo) el analista no es un íntimo del paciente, es éxtimo a esa intimidad. Por lo cual le pertenece una de las definiciones que se dan de éxtimo: algo que sin dejar de estar incluido, no es del mismo tejido que lo que lo rodea.

La función desidentificadora del éxtimo es una de las mayores virtudes para sostenerla siempre presente, de alguna manera, en nuestras Escuelas, en nuestras instituciones, en nuestros dispositivos. La presencia éxtima permite despertar de las ficciones de la grupalidad, trabajar sin descansar demasiado en la comodidad de la tradición o resguardar la tarea de los exabruptos de los narcisismos.

La extimidad se revela imprescindible en la vida de nuestra comunidad de trabajo. Una de sus consecuencias es que no toda agresión es producto de la tensión imaginaria del a-a'. Miller (2010) toma un capítulo entero al que nombra racismo. Y toma la raza tal como la definía Lacan (1984): una raza se constituye por el modo en que se transmiten por el orden de un discurso los lugares simbólicos.

La raza como efecto de discurso, el Otro lo es por poseer algo que no es de ningún modo universalizable y eso es el modo de goce. El odio del racismo es mucho más que agresividad y apunta a lo real en el Otro. Se odia el modo de goce del Otro, se lo vigila, se le supone siempre un goce en más o en menos que lo hace detestable, pero no quedan dudas de que goza.

Estas cuestiones tienen sus razones en el estatuto profundo del objeto que es haber sido sustraído por el Otro. El robo del goce, con el que se acusa al Otro de la raza, dice Miller (2010) que en el psicoanálisis lo llamamos castración.

El Otro es Otro dentro uno mismo, la raíz del racismo desde esta perspectiva es el odio al propio goce. Si el Otro está en el interior en posición de extimidad, es también odio que recae sobre sí mismo. Se trata de tolerar o no un goce distinto del mío.

Es así como podemos extender el estatuto de la segregación a diferentes modos de goce, por ejemplo rivalidades políticas o de clase, aún perteneciendo sociológicamente a la misma, la posición ideológico-discursiva genera diferencias irreconciliables por ubicar a los sujetos en lugares simbólicos dispares.

Asistimos así a pensar el racismo, el sexismo, la segregación, el clasismo en su vertiente real, allí donde naufragan las buenas intenciones idealistas universalizadoras y surgen con violencia los discursos de la tradición. 


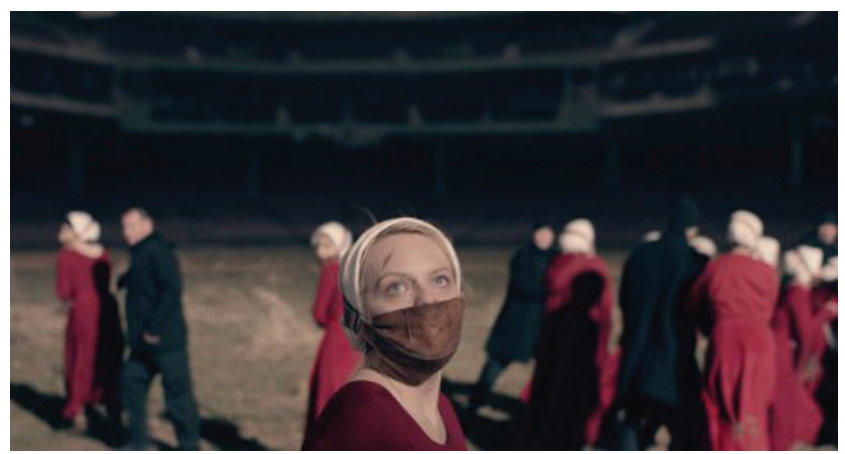

Lo contemporáneo científico había ridiculizado a lo real, también las políticas que desmantelaban recursos sanitarios de los estados en favor de beneficios económicos que se advirtieron cortoplacistas, aún cuando la ciencia retrocedía en su ridiculización y advertía posibles escenarios como el actual. Es un alto precio que estamos pagando por desconocer lo real en juego.

El psicoanálisis se propone como una potente herramienta desidentificadora que reenvía al sujeto a sus determinantes singulares. A partir de ese saldo de saber y del procedimiento al que se sometió para acceder a él no debería poder desconocer sus propias tendencias prejuiciosas, segregativas.

Vemos cómo el arte también va en ese sentido. Son muchas las películas y las series que muestran con un desarrollo estético interesante, los modos que toman los procesos segregativos en el mundo. Más intimistas como Little fires everywhere, asombrosamente futurista sci-fi como Black Mirror o distópicas como El cuento de la criada (por nombrar arbitrariamente sólo algunas) han llevado a la pantalla los padecimientos que se generan cuando el humano desconoce el goce opaco que lo ha colonizado.

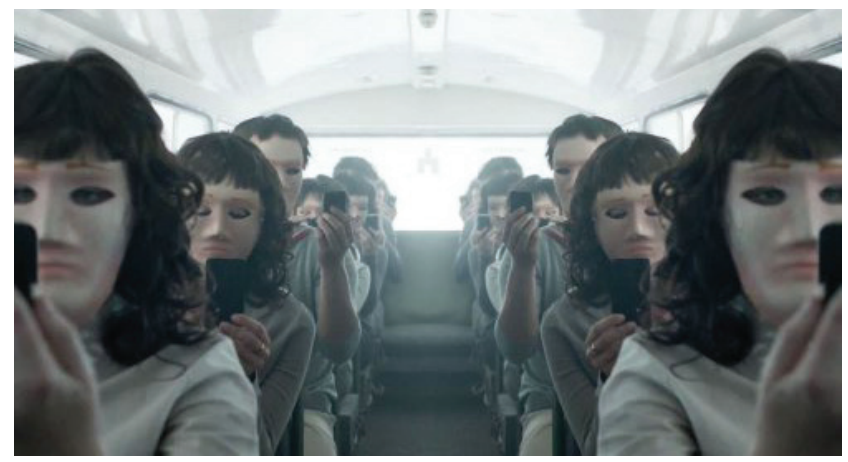

En estos días había hojeado el Diario del año de la peste de Daniel Defoe (1722), el polémico Foe que se escabelizó agregando un De aristocratizante a su apellido. El libro es moralizante, religioso, ficcionado y hasta se lo acusa de plagiado (de su propio tío ya que Defoe era un niño pequeño para 1665) pero son interesante las múltiples coincidencias con nuestra vivencia actual.

He escrito este extremo tan detalladamente, porque no sé si podrá ser de utilidad a aquellos que vengan después de mí, si les aconteciese verse amenazados por el mismo peligro y tuviesen que decidir de la misma manera; por ello, deseo que esta narración llegue a ellos más en calidad de orientación de sus actos que de historia de los míos, puesto que no les valdrá un ardite el saber lo que ha sido de mí.

Me enfrentaba a dos cuestiones importantes: una de ellas era el manejo de mi tienda y mi negocio, que era de consideración y en el que estaba embarcado todo lo que yo poseía en el mundo; la otra era la preservación de mi vida en la calamidad tan funesta que, según veía, iba a caer sobre toda la ciudad y que, sin embargo, por grande que fuese, siempre sería mucho menor de lo que imaginaban mis temores y los de las demás gentes. (Defoe, 1722)

Economía vs. aislamiento obligatorio, clases más pudientes que extienden los márgenes del contagio huyendo a sus fincas fuera de Londres, explotación de los empleados domésticos, movimientos solidarios, fraudulentos, aprovechadores, egoístas, filantrópicos, en fin, la descripción de vastas reacciones humanas en sus múltiples variaciones y...la segregación de los contagiados. Nuevo sector (hoy podríamos agregar al personal de la salud) sobre el cual se instalan reproches, difamaciones o juicios sobre el mayor o menor merecimiento de su condición.

Es interesante confirmar una vez más que lo humano que habita a nivel del goce no se modifica significativamente en el tiempo. Que el racismo, el clasismo, el sexismo son caras de ese rechazo desconocedor de lo propio, de lo profundamente destructivo que anida en el ser hablante pero se dirige al prójimo para intentar controlarlo en su otredad. "La segregación es mala porque no es más que una nueva forma de esclavitud" (M Luther King).

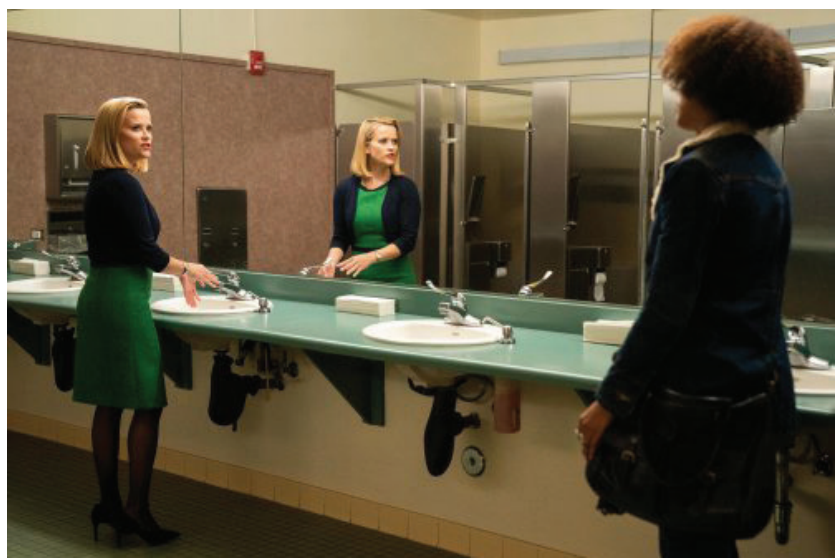




\section{Referencias}

Brooker, C., Jones, A., Reisz, B. (productores) y Brooker, C. (creador). (2011-2019). Black mirror [serie televisiva]. Reino Unido: Zepptron-Endemol.

Defoe, D. (1722). El diario del año de la peste. Reino Unido: Titivillus.

Lacan J. (1984). El atolondradicho. En Escansión 1. Buenos Aires: Paidós.

Lacan, J. (1957). La Instancia de la Letra. En Escritos 1. Buenos Aires: Siglo XXI.

Lacan, J. (1954). El yo en la teoría de Freud y en la técnica psicoanalítica. En El Seminario de Jacques Lacan. Libro II. Buenos Aires: Paidós.

Liffschitz, G. (2009). Un final feliz. (Relato sobre un análisis). Buenos Aires: Eterna Cadencia.

Miller, J-A.(2010). Extimidad. Los cursos psicoanalíticos de Jacques-Alain Miller. Buenos Aires: Paidós.

Moss, E., Miller, B., Atwood, M., Fiore, N., Chaiken, I., Littelfield, W. y Boccia, J. (productores) y Miller, B. (creador). (20172019). The Handmaid's Tale [serie televisiva]. Estador Unidos: MGM Television-Hulu.

Shelton, L.,Tigelaar, L., Washington, K., Savone, P., Witherspoon, R., Neustadter, L. (productores) y Tigelaar, L. (creador). (2020). Little fires everywhere [serie televisiva]. Estados Unidos: Hello Sunshine, Simpson Street, ABC Signature Studios.

$1 \quad$ N. Del E. Término que deriva del inglés actualmente utilizado para referirse a algo aleatorio, fortuito o casual.

2 N. Del E. Expresión que se utiliza una persona en una discusión o debate cuando aporta un argumento que desmonta o desenmascara a su oponente. 